\title{
Charles Peirce's Alternative to the Skeptical Dilemma
}

\author{
LINDA ALCOEE \\ Brown University
}

The problem of skepticism is the paradigmatic philosophical problem, because it is the kind of problem that appears to be elusive of decisive resolution and, thus it is the kind of problem that keeps philosophy in business. Of course, every theory of knowledge attempts to either refute skepticism, explain why we cannot psychologically accept it, or dismiss it as a pseudo problem. But after over 2000 years the problem is still being discussed, with fresh approaches being advanced every other month, from which I conclude that no absolutely decisive and compelling solution to the problem has been as yet formulated.

There are, moreover, no clear proponents of skeptic1sm. Even Barry stroud, the latest champion of taking skepticism seriously. says that skepticism ". . . Is not something we should seriously consider adopting - " 2 So we have a situation in which a particular claim--the claim that we should maintain skeptical doubts concerning the ontological status of the objects of perception-is neither openly defended nor yet decisively refuted.

The best explanation of this situation, which most adequately and coherently explains both our rejection of skepticism and our inability to refute it, is the explanation of the skeptical problem offered by charles Peirce. Peirce's approach has the further advantage of nelther embracing skepticism nor begging the question against skepticism. In what follows I wili try to defend this claim. ${ }^{2}$

The Peircean strategy involves two components. The first component consists in the assertion that the skeptic, say a man, cannot be beat at his own game. Thus, this assertion cedes to the skeptic the view that there is no solution to the skeptical problem on its own terms, in the way that the skeptic sets up the problem. To this extent peirce agrees with the skeptic. The second component of the Peircean approach parts company with the skeptic, however, in his assertion that, because of the cogency of the skeptical problem, we can have no knowledge. Peirce can be said to 
have held that we can have knowledge, but of course to say that may be to equivocate on the meaning of the word 'knowledge'. However, it should become apparent that Peirce's definition of knowledge is not trivial nor a mere linguistic ploy to avoid the skeptical conclusion. In the following essay I will first offer a contentious definition of skepticism and then discuss in turn each of the components of Peirce's approach.

\section{The Skeptical Problem}

There are many versions and varieties of epistemological skepticism, but I will contend that at least most (or the more philosophically tenable) share a basic siteletal framework based on two claims. The first claim is the Pyrrhonian Principle, which states that if the evidence for and against a given proposition is equal, then we should suspend judgement with respect to that proposition. The second claim is that, in fact, the evidence for and against the possibility of knowledge about anything other than the content of our own subjective experiences is equal." From these two clains follows deductively the skeptical conclusion that we should suspend judgement on the possibility of knowledge about anything other than the content of our own subjective experiences. The skeptic does not make a propositional claim, therefore, either that we can or cannot have knowledge of the external world. The skeptic simply withholds judgement. The skeptic is therefore not a solipsist but more like the agnostic to the solipsist's atheism: the latter say "I know that $x$ is not the case" whereas the former say "I do not know whether $x$ is the case or not."

The variety of skeptical arguments is produced by the variety of ways skeptics cash out the second claim, i.e. that the evidence for and against the possibility of knowledge about anything other than the content of our own subjective experiences is equal. Thus one could propose phenomenalism and realism, or realism and evil demons, or evil demons and God, or any combination thereof as equally strong theories, and then using the Pyrrhonian principle deduce the skeptical conclusion. To establish their equality all that needs to be shown is that what justifies one theory can be used equally well to justify a counter theory. Put another way. we might say that two theories are equal when they account for our subjective experiences in equally coherent and comprehensive ways. Surely such equality has been demonstrated. If anything, it seems often the case that realism has less explanatory value than some of its far-fetched and seemingly implausible rivals, as for instance in explaining perceptual mistakes.

Thus it is this two-pronged skeletal framework of the skeptical argument that I will now subject to Peirce, rather than any particularities of skepticism 
such as Descartes's veil of ideas or Putnam's brain in a vat.

\section{Where the Skeptic is Right}

A. J. Ayer, although he is partly gympathetic to Peirce's philosophy, has summarily dismissed Peirce's response to the skeptical dilemma as begging the question against it. Ayer says that in promoting the method of science as the best method for fixing belief and ultimately learning the truth about the world, Peirce "tacitly assumes that the nature of our experience, and so of the world which it reveals to us, is such that it cannot withhold its secrets from a scientific ap-

In my view, however, Ayer's analysis is at least partially incorrect. I believe Peirce admitted that the skeptical problem cannot be solved on the skeptic's terms. To the extent this is true. Ayer is wrong to say simply that Peirce begged the question against skepticism: the matter is at least more complex than
that.

In his early essay, "The Eixation of Belief," Peirce states:

If investigation cannot be regarded as proving that there are Real things, it at least does not lead to a contrary conclusion."

Here Peirce is referring to scientific investigation, which was the only method of inquiry that he considered reliable or useful. Thus Peirce admits that science cannot prove or disprove realism or externality, and that evidence cannot therefore be provided against skepticism. To see more clearly why this is so we need to discuss Peirce's concept of doubt.

Peirce held some very strong views on the nature of doubt. Doubt plays a key role in Peirce's epistemology because Peirce considers doubt to be the source of, and impetus for, all inquiry." Doubt is the opposite of belief, and for Peirce "the essence of belief is the establishment of a habit, $n$ r and "our beliefs guide our desires and shape our actions." Belief. for Peirce, is a state of mind, a felt quality or experience that can guide action. Doubt, as the absence of belief, is likewise a felt quality or experience, but it is the inability to act. Whereas belief is a calm and satisfied state, doubt is a feeling of uneasiness and anxlety, for one does not know what to do."

For Peirce, doubt always arises from practice. Since beliefs are tied to, and even defined by, the actions they generate, doubt or the absence of belief arises in the course of acting, specifically when acting comes to a halt." Doubt arises when, for example, we are driving along in our car and come to an unfamil- 
iar intersection, and do not know how to proceed in order to arrive at our destination. Peirce admits that we may feign doubt, as when we are driving along and wonder where the side-roads lead to, and we may even let this idle wondering motivate us to inquiry.22 But the points he emphasizes are (1) that doubt is necessarily tied to an activity that has been interfered with because of an absence of belief, and (2) that doubt motivates all inquiry. Thus in response to doubt we seek the means to establish the beliefs we need to continue our activity.

Now this understanding of doubt must necessarily bracket out skeptical doubts. When Peirce says "nobody therefore can really doubt that there are Reals, "12 he means that such a doubt would simply not be the sort of doubt he defines as "real" doubt. I think it is less dogmatic for our purposes if we simply say that the skeptical doubt is different from Peirce's conception of doubt, and avoid evaluative hierarchies of "real" doubt and "unreal" doubt at this point.

Why is it that skeptical doubts cannot be included in Peirce's definition of doubt? It is because skeptical doubts do not halt practical activity and, because of this, cannot be resolved. To resolve the anxiety we feel at the unfamiliar intersection there are any number of things we can do: we can ask someone where we are and how to get to our destination; we can get the map out of the glove compartment; we can retrace our steps to familiar landmarks; or we can just pick any turn and continue on, hoping to eventualiy find our way. There is no such procedure to resolve the skeptical doubt, because any such action we take or evidence we offer would be equally subject to the skeptical doubt. Any of the ordinary sorts of evidence we might offer in defense of the claim that our perceptual experience really does indicate the way the world is would be subject to the alternative explanations the skeptic offers--the evil demon, scientists keeping our brain in a vat, etc.--and there just would be no evidence that the skeptic could not challenge. This is because the skeptical doubt does not arise from practice; it is not the case that we believe in externality until we come to an unfamiliar place from which we do not know how to proceed. What is the purposeful activity obstructed by skeptical doubt? There really is none, and so inquiry motivated by skeptical doubts has no clear direction, no end-point of activity it is trying to achieve or justify. Skepticism does not arise out of activity nor is its resolution motivated by a felt need for guidance in our actions. The skeptic says all our actions are entirely consistent with any number of alternative metaphysical explanations. and it is precisely this equal consistency that gives the skeptical problem its force as a dilemma. There just is nothing we can offer to refute the possibility 
of alternative explanations of experience. This is why skepticism has never been refuted. If skepticism were tied to our activity in any way, then its force would be diminished and there would be a procedure for its resolution. The skeptic realizes that by disassociating his skeptical doubt from any experiential considerations or effects his argument is truly irrefutable.

It is this disassociation from activity that leads Peirce to opine that the skeptical doubt can "not be a source of dissatisfaction" and therefore is not a real doubt. 13 We can have no felt experience of anxiety or uneasiness in regard to a skeptical doubt because it cannot affect our activities in any way. Stanley Cavell has argued that this assumption is unfair. Cavell wants to say that the skeptical doubt can be a felt experience, and by implication therefore Peirce must be wrong to dismiss skeptical doubts as not genuine. ${ }^{14}$ I think that Cavell may indeed have a valid point but that this point does not repudiate Peirce's overall thesis. Let me explain.

It is not inconceivable that a person who believes that some significantly divergent alternative explanations of their perceptual experiences are equally possible might feel some anxiety or uneasiness. Thus Cavell's point is well taken: the skeptic may experience the skeptical doubt as a felt quality, and therefore the skeptical doubt cannot be casuaily dismissed by Peirce as not genuine. However, a distinction still needs to be made between the skeptical doubt and the other sorts of doubt Peirce discusses. We cannot resolve the skeptic's doubt any more than we can resolve a doubt over whether the earth was created five minutes ago just as it is now. Moreover, we cannot even fathom what the procedure would look like by which we could come to resolve such doubts. These facts must mark off such doubts as skeptical doubts and whether the earth was created five minutes ago from doubts such as whether we should turn right or left to get to Pawtucket Avenue or even whether there are any living creatures in the next galaxy over. For even though we may never have the means to resolve the latter doubt. we can spell out the basic procedure necessary for it to be resolved. Thus, Peirce can admit that cavell is right to say that skeptical doubts are a type of doubt. but still hold to a distinction between doubts that are not resolvable in principle ard doubts that are resolvable in principle.

Making a distinction between these kinds of doubt has the advantage of clarifying why it is that skepticism cannot be refuted. It is not a doubt of the second type and is therefore not resolvable in principle. Now notice that classifying the skeptical problem in this way is not to say that it is a pseudo problem and noţ genuine, something which I do not think Peirce believed. Skepticism is a genuine problem in that it 
asks for evidence that we cannot provide. It is because we cannot provide this evidence that peirce rejected the correspondence theory of justification and moved to fallibilism. Because Peirce admits that science cannot prove "that there are Real things" is" he cannot use correspondence as a criterion for knowledge," and says that the object of inquiry can only be the settlement of belief. '1 Peirce does not argue, as some philosophers have, that the problem of skepticism is entirely vacuous or that the terms in which the skeptical problem is posed have no meaning.

So it appears that, even though Peirce wanted to say no one can "really doubt" the existence of Reals, we cannot conclude from this that Peirce dismissed skepticism as a pseudo" problem or believed that he could refute it. Peirce ceded to the skeptics their position that the skeptical dilemma is a real problem in that it cannot be facilely dismissed or refuted. Peirce recognized that, if we accept the skeptical problem on the terms that the skeptic lays out, there is no way to refute $1 t$. We cannot even imagine what procedure to follow to resolve the skeptic's doubt.

In the following section I would like to discuss what Peirce did not cede to the skeptics, $1 . \theta$. the view that because of the skeptical problem we must suspend all judgement.

\section{Where the Skeptic is Wrong}

Leaving aside the skeptical argument for the moment, I will discuss Peirce's reasons for believing we are justified in asserting the possibility of knowledge beyond our subjective experiences. These reasons constitute Peirce's alternative to skepticism, and both explain and justify our actual assertion of the possibility of knowledge, without providing an argument which refutes skepticism.

First we must discuss Peirce's understanding of knowledge. What Peirce calls knowledge is justified belief, and truth is not distinct from justified belief. That is, Peirce claims at one and the same time that truth is logically distinct and practically indistinct from belief: although believing $x$ does not make it true we have no means of ascertaining truth above and beyond our method of justifying belief. Therefore, the concept of justified true belief contains a redundancy. Knowledge can simply be defined as justified belief, always uncertain and revisable in the light of future experience. This is clearly a different conception of knowledge than the skeptics
held.

Exploration of Peirce's theory should not stop here, else it might appear that Peirce easily slips out of the skeptic's grasp by a simple linguistic tactic-redefining knowledge so that we can say we have 
knowledge even though we cannot have the kind of knowledge the skeptic wants. Actually, Peirce's view is much more interesting than that.

For Peirce the concepts of belief and doubt, and consequently knowledge given Peirce's equation between knowledge and justified belief, are inextricably tied to practical activity. This is not because justified belief is useful belief but rather because belief is a cause of activity and so "different beliefs are distinguished by the different modes of action to which they give rise." 20 . We come to have doubts and are led to inquire because we need a guide to action; we need to know which turn to take to reach our destination or purpose, which for Peirce is never belief alone but always an activity.

This view must not be mistaken for the view that all scientific activity is practical in the sense of having a specific practical purpose as a goal of any experiment or inquiry. Peirce adamantly opposed this view, and went so far as to say that such researchers as business employs to solve some practical problem "do not rank as genuine scientific men."2l For Peirce, the scientific attitude is exemplified by its disinterest in practical affairs and its pursuit of knowledge for its own sake. 22 Thus, in relating belief and doubt to actions and effects Peirce is not making practical goals the motive force or standard of science. Rather, he is simply arguing that belief and doubt cannot be entirely disassociated from their observable, verifiable results. Peirce's pragmatic maxim goes as follows:

Consider what effects, that might conceivably have practical bearings, we conceive the object of our conception to have. Then, our conception of these effects is the whole of our conception of the object.23

To the extent that the object of our conception is a proposition which entails no effects, our conception of it is therefore problematic.

None of this so far, however, tells us how belief is justified. We have already stated that peirce believes the method of science is the best method of justifying belief, but why is this so unless we can prove that science gives us a picture of reality that corresponds to the real thing?

It is clear that Peirce believed that science does give us a correct picture of reality, 20 although the current picture is not wholly correct.25 Here is where Ayer says Peirce begs the question against the skeptic by making a very big assumption and, within narrow limits, I think Ayer is right. But there are some good reasons Peirce gives for relying on science, one of which I will discuss. Peirce argues that science is the best method for settling opinion. In order to un- 
derstand this claim we need to see why Peirce thinks science is the best method and what epistemic significance the mere settling of opinion has, since even a consensus of opinions may, of course, be erroneous.

Science is the best method for settling opinion because it yields more intersubjective conclusions than any other. All other methods involve greater degrees of human subjectivity. Peirce discusses tenacity (holding onto an opinion until it becomes entrenched). authority, and the a priori method of justifying belief, and he notes that each of these methods lead too often to irremediable differences of opinion. Science, which is based on something less open to subjective dickering, yields a more permanent and stable belief. 26 (It is not necessarily begging the question against skepticism to assume science's intersubjectivity. Even the person who believes she may be a brain in a vat must recognize the qualitative distinction between individual control over one's beliefs based on science and over one's beliefs based on the a priori method.)

To satisfy our doubts, therefore, it is necessary that a method should be found by which our beliefs may be determined by . . . something upon which our [individual] thinking has no effect. 27

Thus science yields intersubjective conclusions and therefore settles opinions better than any other methcd. All we need to argue in defense of this view is not that science telis us the way the world is but that we have less conscious control over the outcome of scientific inquiry than we have over inquiry based on any other method, and surely this is the case. Therefore, the method of science is the best method to use for settling opinion.

But why should we be concerned with settling opinion? It is because to hold a belief which is not shared by others or which does not represent a consensus of opinion within one's sphere of acquaintances is to invite doubt, and hence to invite that feeling of uneasiness which is entailed by doubt and is the obstacle to habit. ${ }^{\circ}$

Unless we make ourselves hermits, we shall necessarily influence each other's opinions, so that the problem becomes how to fix belief, not in the individual merely, but in the community.29

The presence of beliefs contrary to our own inclines us to question and doubt our own beliefs. Therefore, if we wish to have a stable belief to guide our actions and dispel that feeling of anxiety and uneasiness that doubt brings with it, our goal should be to reach settled opinions with as high a degree of consensus as possible. Science, because of its reliance on inter- 
subjective experience and its demand for repeated testability, is the best method for achieving a consensus of opinion. Moreover, the method of science also involves accounting for a wider scope of opinions and experience than any other method, " and so is for this reason also less likely to allow conflicting opinions and the consequent emergence of doubt. Thus, science is the best method of fixing belief and dispelling doubt.

Now, what is the relevance of science to the assertion of the possibility of knowledge beyond our subjective experiences? Peirce's argument goes as follows: (1) All inquiry is motivated by doubt in order to establish habits of action. (2) The method of science is the best method of dispelling doubt and establishing habits of action. We have seen this in science's ability to achieve greater consensus. (3) science presupposes that we can have knowledge about more than the content of our subjective experiences.31 Thus what Peirce is arguing is that all inquiry, or the pursuit of belief, must presuppose knowledge beyond subjective experience. Whenever we inquire, we are therefore justified in accepting the possibility of such knowledge.

Could the skeptic at this point argue that, if inquiry necessitates presupposing the possibility of knowledge beyond our subjective experiences, then in withholding belief as the skeptic advocates we are withholding inquiry, and thus are not forced into a commitment to the possibility of such knowledge? It seems such an argument must fail to the extent inquiry entails belief and to the extent we cannot withhold all beliefs about such knowledge. It seems clear that all actions presuppose belief. If I walk over to a chair and sit down I presuppose that my subjective experience of a chair-image correlates to the image's ability to hold my weight. If I choose to become a hedonist I presuppose that certain actions will correlate to certain pleasures. All actions presuppose some beliefs that extend beyond my subjective experience, and yet we act at every conscious moment. Even suicide is an action which presupposes some belief. We cannot not act, and to act is to presuppose belief, and to believe is to presuppose that we can have knowledge beyond the content of our own subjective experiences. Therefore we cannot act in a way that is consistent with skepticism.

This is not a psychological argument on the order of Hume's because where Hume relies on the psychological characteristics of the human mind, Peirce bases his argument on the coherence between belief and action.

Skepticism is neither a belief nor a doubt, using Peirce's definitions. Skepticism is not a belief since it is the withholding of belief, and yet it is not a doubt in Peirce's sense because it does not halt activ- 
ity. So skepticism neither generates habits of action nor does it halt them. Since all actions presuppose belief, and since in the pursuit of consistent beliefs we must use the method of science, we must presuppose, as in fact we all do, that knowledge about more than the content of our own subjective experiences is possible. For Peirce, this is a justified hypothesis.

Setting up the argument in this way demonstrates that Peifce does not really beg the question against the skeptic. Peirce does not assume the skeptic is wrong in saying that we have no proof of realism. Rather, Peirce argues that we can only adopt skepticisi at the expense of coherence. In "The Essentials of Pragmatism" he says:

- what you cannot in the least help believing is not, justly speaking, wrong belief. In other words, for you it is the absolute truth. True, it is conceivable that what you cannot help believing today, you might find you thoroughly disbelieve tomorrow. But then there is a certain distinction between things you 'cannot' do, merely in the sense tinat nothing stimulates you to the great effort and endeavors that would be required, and things you cannot do because in their own nature they are insusceptible of being put into practise."2

Thus, our belief in the possibility of knowledge is absolutely justified according to the standards Peirce thinks are important, i.e. our ability to doubt it in such a way that it affects our activity. And our ability to doubt cannot be subjectively willed but is determined by the nature of the belief in question and its relation to our activity; thus there is a form of objectivity in Peirce's epistemology.

Nevertheless, Peirce cedes to the skeptic his contention that we cannot provide a foundational grounding for realism which will assuage the skeptical doubt. I conclude from Peirce's admission of this fact and his subsequent move to a non-foundational epistemology that characterizing Peirce's position toward skepticism as one of dismissal is a distortion. It seems to me that Peirce's epistemology exemplifies precisely what Barry Stroud advocates: taking skepticism seriously not in its viability as a warranted assertion but in its forcing us to pursue the question of what a philosophical theory of knowledge is actually supposed to do and "how our familiar everyday knowledge actually works."3" It seems fairer, then, to characterize Peirce's position on skepticism as arguing not that it is a pseudo problem or even a pseudo doubt but simply a doubt unresolvable in principle and incapable in principle of affecting actions in any way. And as a matter of fact, except for some very old rumors about Pyrrho, " we know 
of no skeptic who attempted to change his behavior because of his skeptical doubts. Peirce concludes from this, and his theory of belief and doubt, that we cannot make the skeptical conclusion, even while we cannot refute it. All inquiry presupposes knowledge beyond our subjective experiences, and therefore this belief is warranted. Thus Peirce provides, not a refutation of skepticism, but an alternative to it.

\section{NOTES}

"Barry Stroud, "skepticism and the Possibility of Knowledge," Journal of Philosophy 81 (Oct. 1984): 545.

'Peirce's voluminous writings have inspired many charges of inconsistency and even incoherence. As with any long dead author who wrote so much so unsystematically, I will have to claim only that I am reconstructing what I interpret to be his approach to the skeptical problem gleaned from various key passages.

'Note the use of the word 'our' instead of 'my'. I will be dealing here only with skepticism toward an externality outside of mind, and will not deal with skepticism toward the existence of other minds. The significance of this will become clear in the last section where I discuss Peirce's defense of the method of science.

'A. J. Ayer, The Origins of Pragmatism (London: MacMillan, 1968), 39 .

"Charles Peirce, "The Fixation of Belief," in The Philosophy of Peirce, ed. Justus Buchler (London: Routledge and Kegan Paul, 1940), 18.

"Peirce, "The Eixation of Belief," 10. It is interesting that doubt plays such a pivotal role in the epistemologies of both Descartes and Peirce, though they end up in such diverse positions. Descartes thinks that by following doubt we will eventually reach infallibility and Peirce thinks no such infallibility exists but that we can still eliminate doubt. Obviously, their difference is over how to define doubt.

"Peirce, "How To Make Our Ideas clear," in The Philosophy of Peirce, 29.

"Peirce, "The Eixation of Belief," 9-10.

'Peirce, "The Fixation of Belief," 10 . 
${ }^{10} \mathrm{He}$ discusses this throughout the essay "How To Make Our Ideas Clear."

"Peirce, "How To Make Our Ideas clear," 27.

12 Peirce, "The Eixation of Belief," 19.

1 "Peirce, "The Fixation of Belief," 19.

"Stanley Cavell, The Claim of Reason (New York: Oxford University Press, 1979$), 140 \mathrm{ff}$.

${ }^{13}$ Peirce, "The Fixation of Belief," 18.

${ }^{16}$ There is some controversy over whether Peirce does reject the correspondence theory of truth, given his view that the scientific community will ultimately come to the true nature of reality. But it is clear that for Peirce we cannot claim correspondence for any particular proposition at any time because all knowledge is revisable in the light of future experience and we will never know when we have reached the final irreversible opinion which does in fact correspond. For a full discussion of the conflicting interpretations of Peirce's theory of truth see Robert Almeder, "Peirce's Thirteen Theories of Truth," forthcoming in The Transactions of the Charles S. Peirce Society (Winter 1985). See also in the same journal Almeder's "Peircean Fallibilism" (Winter 1982): 5765.

1'Peirce, "How To Make Our Ideas Clear," 38; see also "the Eixation of Belief," 10; and Ayer, 20-22.

1"See Almeder, The Philosophy of Charles S. Peirce, (Totowa, New Jersey: Rowman and Littlefield, 1980)', 119-20; and also The Collected Papers of Charles Peirce, ed. C. Hartshorne and $\bar{P}$. Weiss (Cambridge: Harvard University Press, 1935), 5:416. 22-23.

"Peirce, "The Fixation of Belief," 10; and Ayer,

$2{ }^{\circ}$ Peirce, "How To Make Our Ideas Clear," 29.

21Peirce, "The Scientific Attitude and Eallibilism," in The Philosophy of Peirce, 42 .

22Peirce, "The Scientific Attitude and Eallibil-
ism, $43-47$.

2 "Peirce, "How To Make Our Ideas clear," 31.

2"It is clear, at least, that Peirce believed this, though he had doubts at various times whether it could 
be proved. See Almeder's "Peirce's Thirteen Theories of Truth," 12-14.

${ }^{23}$ Peirce, "The Fixation of Belief," 21.

${ }^{26}$ Peirce, "The Fixation of Belief," 18-19.

27 Peirce, "The Fixation of Belief," 18.

2 "Peirce, "The Fixation of Belief," 12.

2 "Peirce, "The Fixation of Belief," 13.

30 Ayer, 34.

"Peirce, "The Fixation of Belief," 18.

32 Peirce, "The Essentials of Pragmatism," 258.

33arry Stroud, The Significance of Philosophical Skepticism (Oxford: Clarendon Press, 1984), 256.

"See M. F. Burnyeat, "Can the Skeptic Live His Skepticism?" in The Skeptical Tradition, ed. M. F. Burnyeat (Berkeley: University of California Press, 1983), 124. 